\title{
The fracture testing of ductile polymer films: Effect of the specimen notching
}

N. León ${ }^{\mathrm{a}, *}$

noel.leon@estudiant.upc.edu

A.B. Martínez

P. Castejón ${ }^{\mathrm{a}}$

D. Arencón ${ }^{\mathrm{a}}$

P.P. Martínez

${ }^{a}$ Centre Català del Plàstic, Departament de Ciència dels Materials i Enginyeria Metal-lúrgica, Universitat Politècnica de Catalunya, BarcelonaTech, C/Colom 114, 08222 Terrassa, Spain

b NUDEC SA, C/ Pintor Vila Cinca, 24-28, Pol. Ind. Can Humet de Dalt, 08213 Polinyà, Spain

${ }^{*}$ Corresponding author.

\section{Abstract}

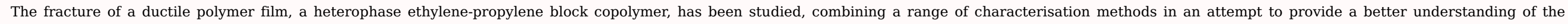

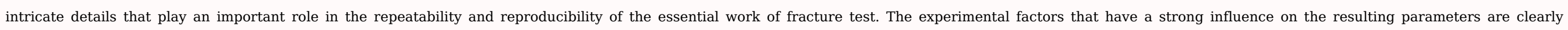

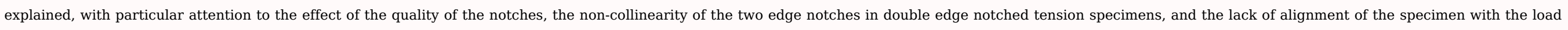

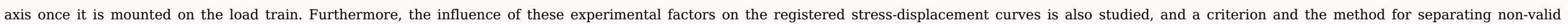
specimens are established.

Keywords: Fracture; Essential work of fracture; J-integral; Polymer film

\section{Introduction}

Polymer films are used in a wide variety of applications. Their toughness is often a basic requisite to meet some industry needs.

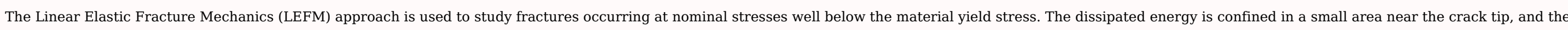

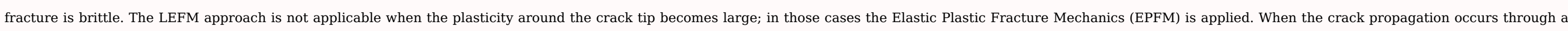
highly deformed and yielded material then Post-Yield Fracture Mechanics can also be applied and the Essential Work of Fracture (EWF) is a suitable methodology.

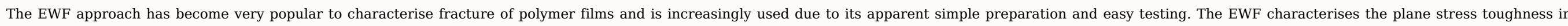
mode I, generally using the double edge notched tension (DENT) configuration for the specimens.

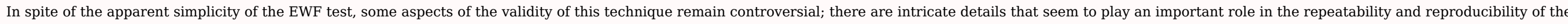

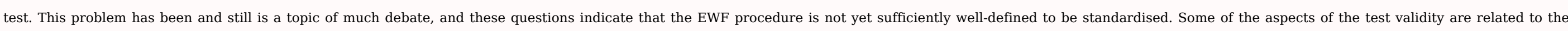
specimen manufacture, particularly the quality of the notches.

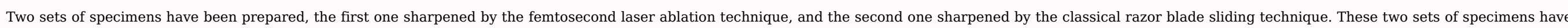




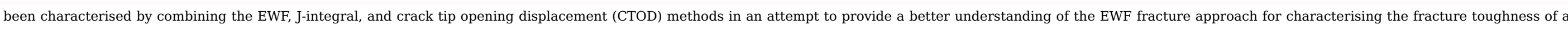

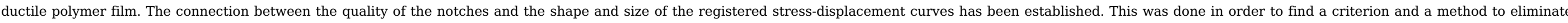
non-valid specimens. Furthermore, it has been studied in detail how the size and shape of the stress-displacement curves are related to the EWF fracture parameters.

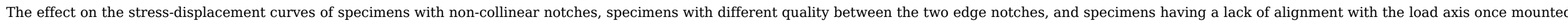
on the testing machine grips have been also studied.

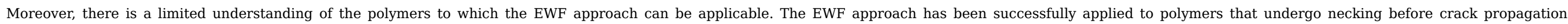

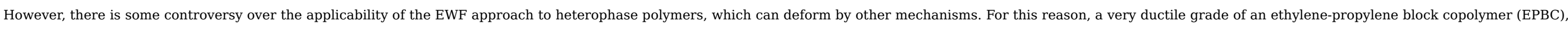
which is prone to plastic deformation and thus problematic for the notch sharpening, was tested.

The main objective of this work is to contribute to a better understanding and to clarify some of the controversial factors involved in the EWF test.

\section{The EWF approach}

\subsection{The EWF concept}

The EWF approach [1] is based on the hypothesis that the total energy involved during the ductile fracture of a pre-cracked specimen $\left(\mathrm{W}_{\mathrm{f}}\right)$ can be separated into two terms

$$
\mathrm{W}_{\mathrm{f}}=\mathrm{W}_{\mathrm{e}}+\mathrm{W}_{\mathrm{p}}
$$

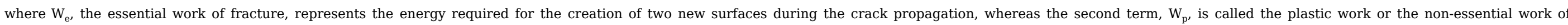

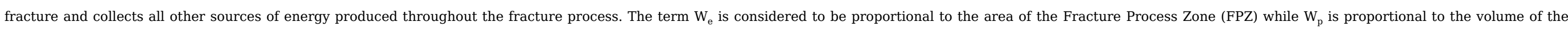
Outer Plastic Zone (OPZ). These zones are schematised in Fig. 1 for a DENT specimen.

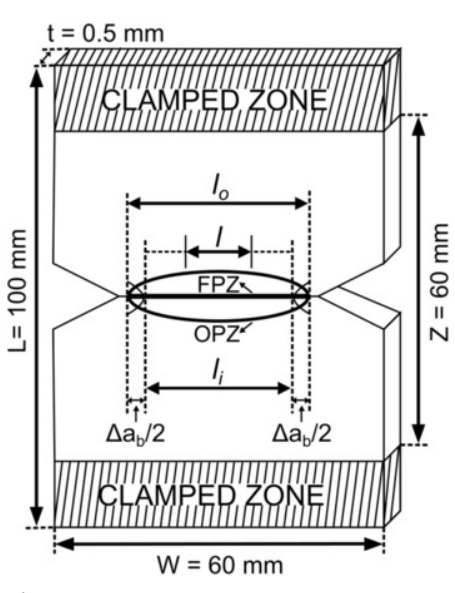

Fig. 1 DENT specimen geometry.

alt-text: Fig. 1

Rewriting Eq. (1) using specific terms,

$$
w_{\mathrm{f}}=\frac{\mathrm{w}_{\mathrm{f}}}{\mathrm{l}_{\mathrm{o}} \mathrm{gt}}=\mathrm{w}_{\mathrm{e}}+\beta \mathrm{w}_{\mathrm{p}} \cdot \mathrm{l}_{\mathrm{o}}
$$

where $t$ is the specimen thickness, $l_{0}$ is the original ligament length and $\beta$ is a factor that depends on the shape of the OPZ.

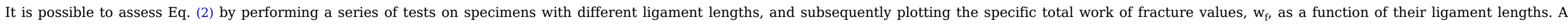




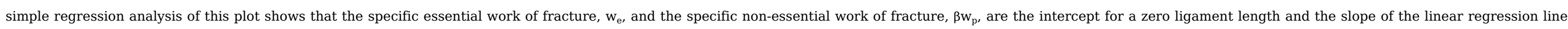
respectively.

The value which represents the toughness, namely, $\mathrm{w}_{\mathrm{e}}$, is an inherent material parameter only if the ligament yields fully before the onset of crack propagation.

\subsection{Key assumptions}

In the EWF analysis, the following three basic key assumptions are made:

a) The $l_{0}$ is fully yielded prior to the onset of crack propagation.

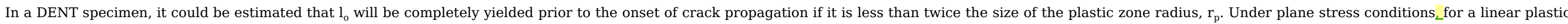
zone

$2 r_{p}=\frac{\pi}{8}\left(\frac{E w_{e}}{\sigma_{y}^{2}}\right)$

and for a circular plastic zone

$2 \mathrm{r}_{\mathrm{p}}=\frac{\mathrm{Ew}_{\mathrm{e}}}{\pi \sigma_{\mathrm{y}}^{2}}$

where $\mathrm{E}$ is the elastic modulus and $\sigma_{\mathrm{y}}$ is the uniaxial yield stress.

Although having $\mathrm{l}_{\mathrm{o}} \leq 2 \mathrm{r}_{\mathrm{p}}$ is a reasonable size criterion, it appears to be too restrictive.

b) Fracture occurs under plane stress conditions.

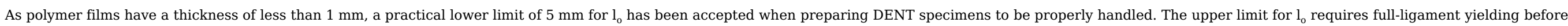
crack propagation. Hence, $l_{o}$ has to be less than twice $r_{p}$ in DENT specimens.

Another upper limit is given by the relationship:

$1_{\mathrm{o}} \leq \frac{\mathrm{W}}{3}$

where $\mathrm{W}$ is the specimen width. This last condition is necessary to prevent edge effects.

c) Good quality notches

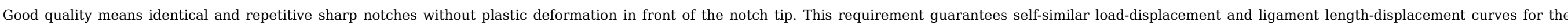
tested specimens $[2,3]$.

The notch sharpening is of critical importance in obtaining good results [4-6]. The larger notch tip radius or plastic deformation, the higher $\mathrm{w}_{\mathrm{e}}$ values.

\subsection{Other considerations}

When the key assumptions are satisfied, $\mathrm{w}_{\mathrm{e}}$ is the specific energy just before crack initiation. That is, an initiation value which coincides with the J-integral value at initiation, $\mathrm{J}_{\mathrm{o}}[2]$.

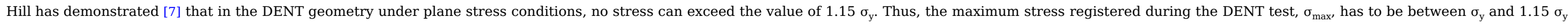

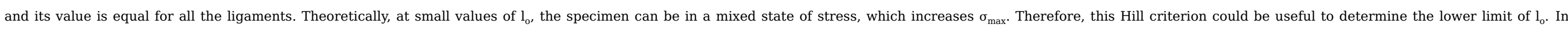

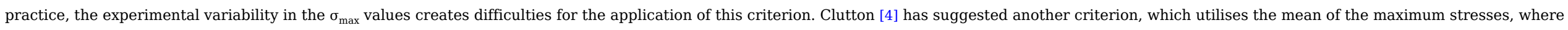


This criterion only removes data where an error in dimensional measurement or in load exists.

\section{Experimental details}

\subsection{Material}

The study has been conducted on a commercial grade of EPBC. The microstructure consists [8] of elastomeric ethylene-propylene particles embedded in a polypropylene matrix

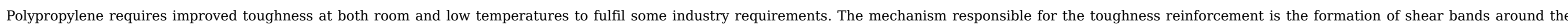
elastomeric particles, which absorbs most of the deformation energy.

The raw material in the form of pellets was kindly supplied by REPSOL. Films that were $0.5 \mathrm{~mm}$ thick were cast-extruded from the pellets.

\subsection{Specimen preparation}

Two kinds of specimens were prepared: dumbbell shaped and DENT specimens. All the specimens were prepared and tested in the machine direction orientation.

Dumbbell shaped specimens were obtained in a cutting press with the shape and dimensions of ISO 527-3 type V specimen.

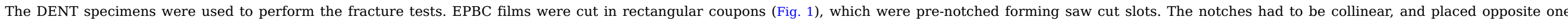
another at the midpoint of the specimen height.

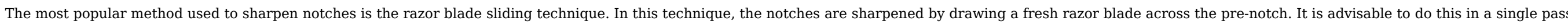

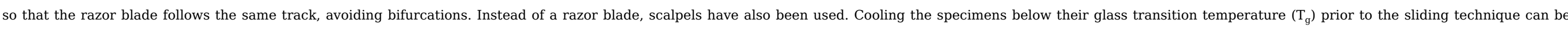

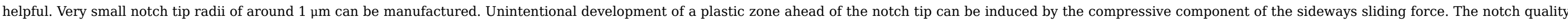
is depending on the technique used, and even on the operator skill.

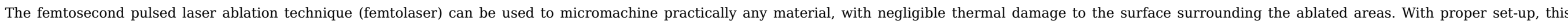
technique allows obtaining consistent notches that have negligible thermal damage, no plastic deformation, and a notch tip radius of approximately $1 \mu \mathrm{m}[2,3,6]$.

The sharpening of the pre-notched EPBC specimens was carried out using two different methods, the femtolaser ablation technique and razor blade sliding.

In one set of 18 specimens, the machined pre-notch was extended by the application of the femtolaser ablation technique with the same set-up and other variables, as defined for another EPBC grade [6].

The second set of 18 specimens was sharpened by manually sliding a new razor blade across the pre-notch in a single pass.

The $\mathrm{l}_{\mathrm{o}}$ of each specimen was measured after testing in an optical microscope.

One surface of each specimen was adequately sprayed with a speckle pattern before being tested.

\subsection{Test conditions}

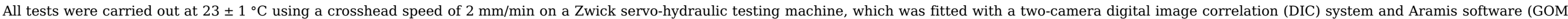
Germany)

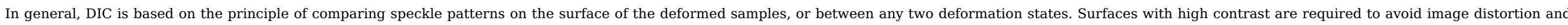
therefore inaccurate data. Hence, before testing, one surface of each specimen was covered with a thin white coating before being sprayed in order to obtain black points, as required by the DIC system.

Uniaxial tensile tests were performed on the dumbbell shaped specimens. The load was registered by the load cell and the displacements by the DIC system. 


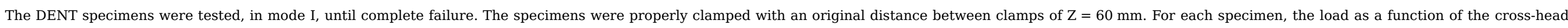
displacement, $d_{z}$, was registered.

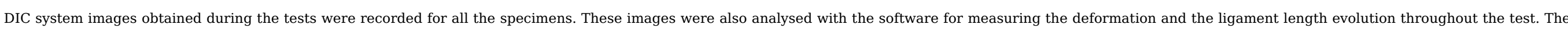

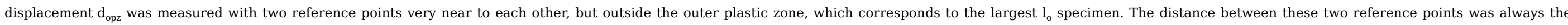

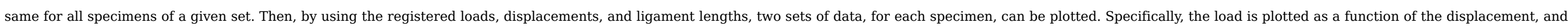
the ligament length 1 as a function of the displacement.

\section{Results and discussion}

\subsection{Uniaxial tensile test}

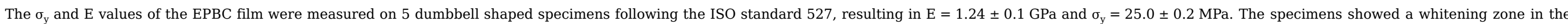
deformed area, which is characteristic of the heterophase polymers.

\subsection{Notch quality}

The notches of two specimens from each set were observed by optical light microscopy and also by scanning electron microscopy (SEM).

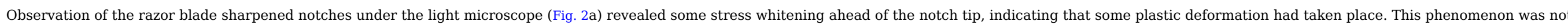
present in the notches of the femtolaser specimens (Fig. 2b).

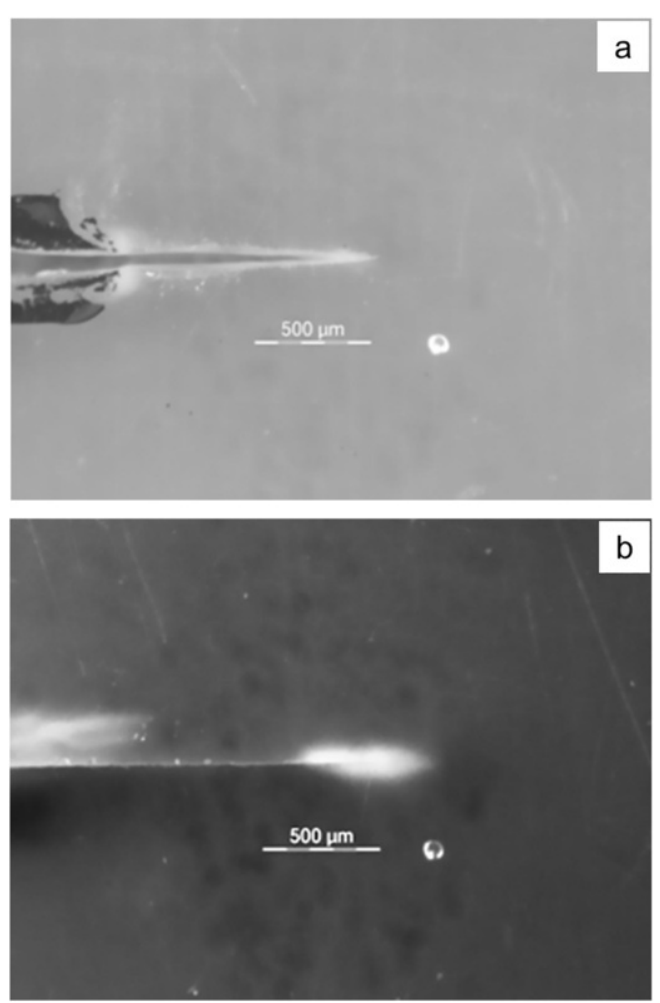

Fig. 2 Optical micrographs: a) Femtolaser notch, b) Razor blade notch. 


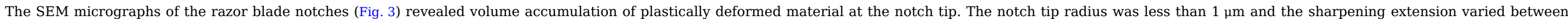
900 and $1300 \mu \mathrm{m}$

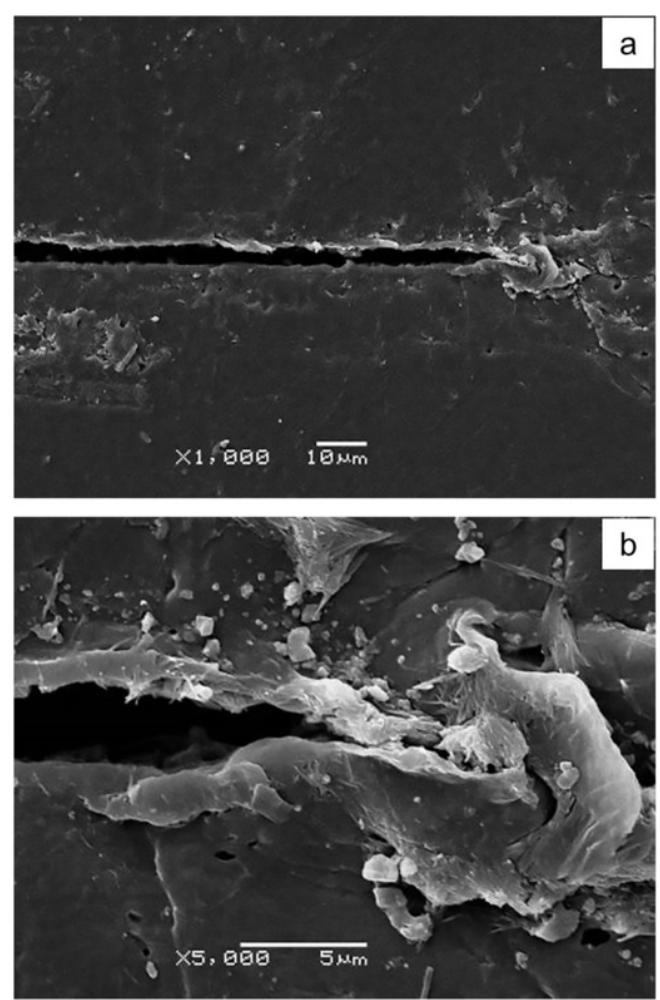

Fig. 3 SEM micrographs of a razor blade specimen: a) Extended notch, b) Notch tip detail. alt-text: Fig. 3

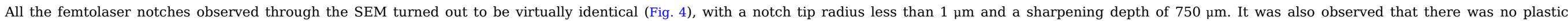
deformation and negligible thermal damage at the notch root. 

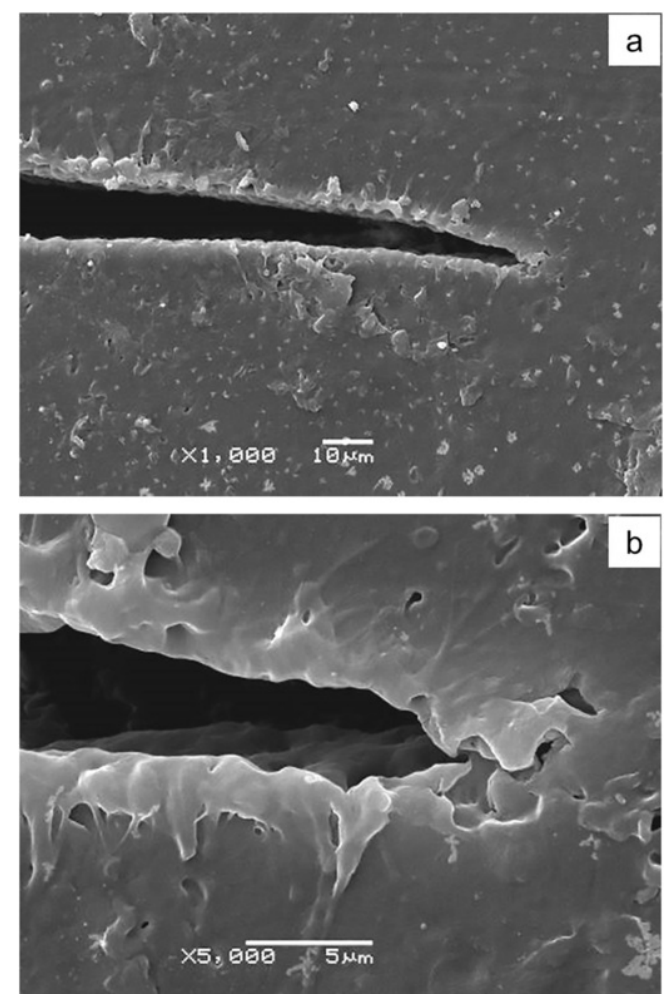

Fig. 4 SEM micrographs of a femtolaser notch: a) General view, b) Detail of the crack tip. alt-text: Fig. 4

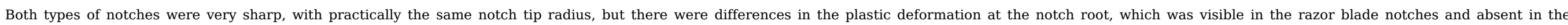
femtolaser ones.

The second phase particles of the EPBC act as stress concentrators, and so only a small compressive component of the sliding force is needed to produce plastic deformation, which is visualised as whitening

\subsection{Femtolaser specimens}

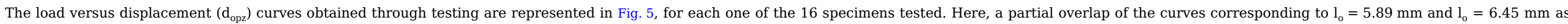
well as the curves $l_{o}=19.37 \mathrm{~mm}$ and $l_{o}=20.39 \mathrm{~mm}$ can be observed. 


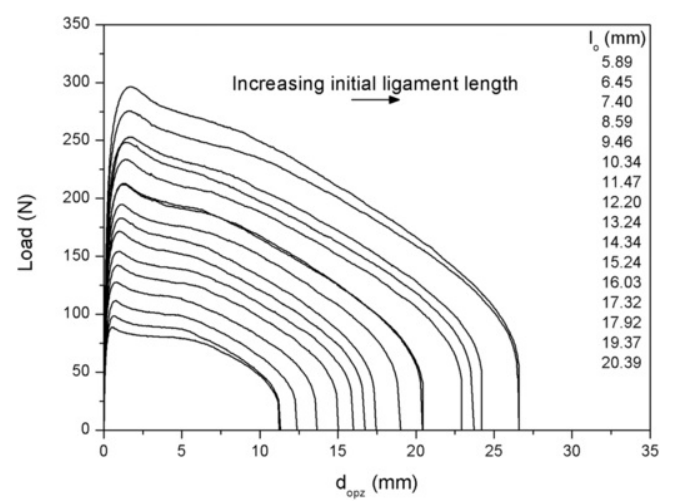

Fig. 5 Registered load-d $\mathrm{d}_{\mathrm{opz}}$ curves for the 16 femtolaser specimens.

alt-text: Fig. 5

The ligament lengths (l) as a function of the displacement $\left(\mathrm{d}_{\mathrm{opz}}\right)$ are represented in Fig. 6 for the same 16 tested specimens. As in Fig. 5, a partial overlap is also observed for the same $\mathrm{l}_{\mathrm{o}}$ curves.

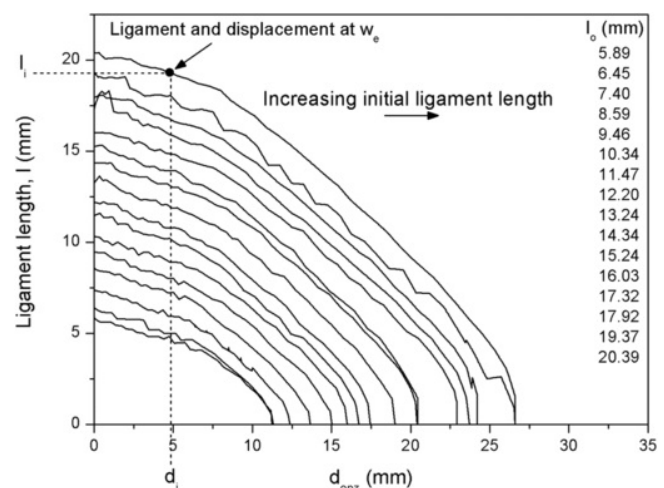

Fig. 6 Registered 1 versus $d_{\text {opz }}$ curves for the 16 femtolaser specimens.

alt-text: Fig. 6

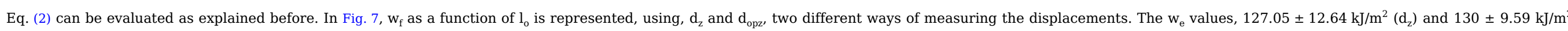
$\left(\mathrm{d}_{\text {opz }}\right)$, are practically coincident but the slopes, $21.35 \pm 0.90 \mathrm{MJ} / \mathrm{m}^{3}\left(\mathrm{~d}_{\mathrm{z}}\right)$ and $19.94 \pm 0.70 \mathrm{MJ} / \mathrm{m}^{3}\left(\mathrm{~d}_{\text {opz }}\right)$, change slightly. 


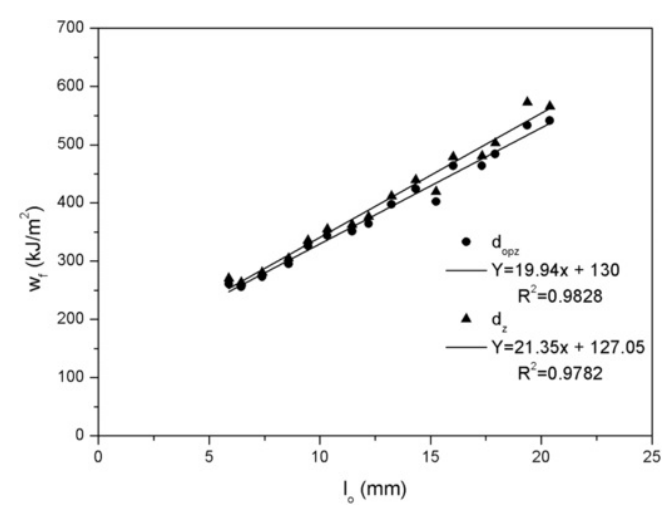

Fig. 7 EWF plot for the 16 femtolaser specimens: $\bullet$ ) Displacement $d_{\text {opz }}$ () Displacement $d_{z}$

alt-text: Fig. 7

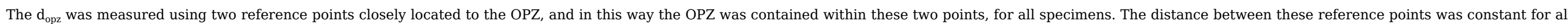

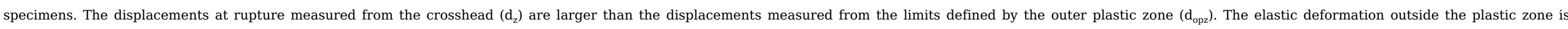
recovered on unloading so that both rupture displacements would be expected to be equal at least that the total recovery of other displacements, as viscoelastic, does not happen before specimen rupture.

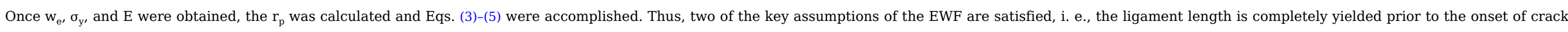
initiation, and fracture is under plane stress conditions.

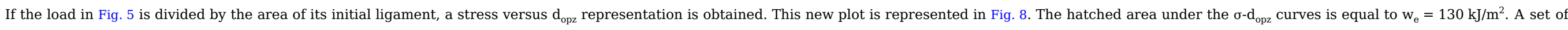

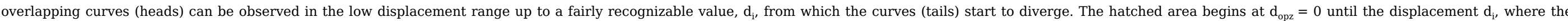

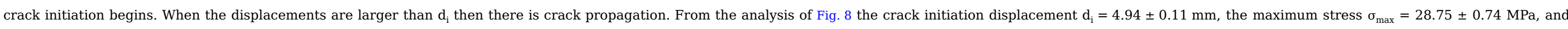
the crack initiation stress $\sigma_{\mathrm{i}}=25.89 \pm 0.46 \mathrm{MPa}$ can be identified.

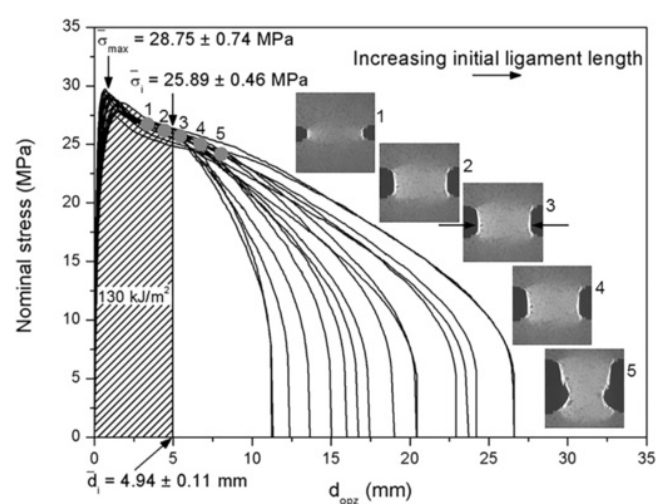

Fig. 8 Stress versus $\mathrm{d}_{\mathrm{opz}}$ curves for the 16 femtolaser specimens.

alt-text: Fig. 8

The $\sigma_{\max }$ values are between $\sigma_{\mathrm{y}}$ and $1.15 \sigma_{\mathrm{y}}$ and therefore Eq. (6) is also valid for all specimens. The Clutton and Hill criteria are now satisfied

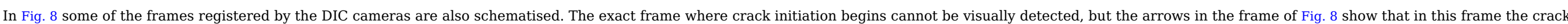




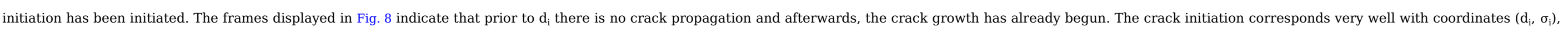

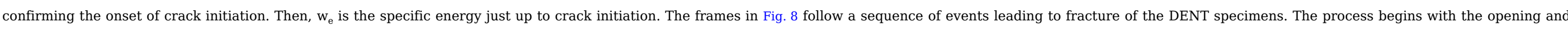
blunting of the notch and the yielding of the ligament area, followed by crack initiation and propagation until complete failure.

The crack tip opening displacement at the onset of crack initiation, CTOD is

$\mathrm{d}_{\mathrm{r}}=\mathrm{CTOD}+\alpha \cdot \mathrm{l}_{\mathrm{o}}$

where $d_{r}$ is the displacement at complete rupture.

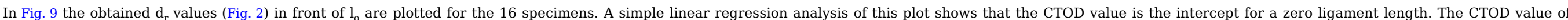
$4.94 \mathrm{~mm}$ is coincident with $\mathrm{d}_{\mathrm{i}}$ the displacement at the onset of crack initiation (Fig. 8).

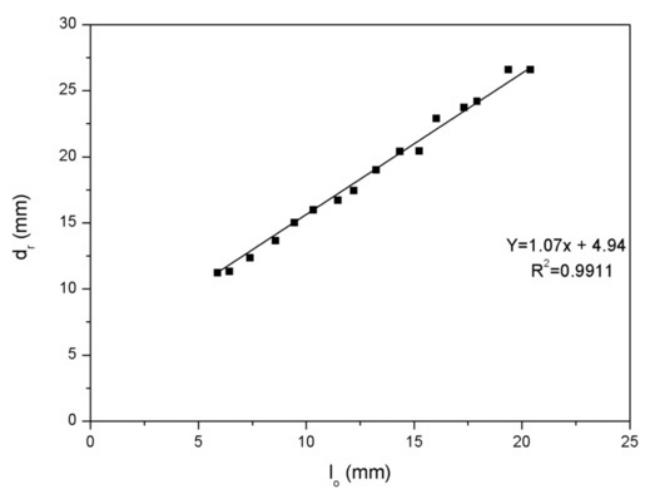

Fig. 9 Determination of CTOD for the 16 femtolaser specimens.

alt-text: Fig. 9

The crack length increment due to blunting, $\Delta \mathrm{a}_{\mathrm{b}}$, just prior to crack initiation is given (Fig. 1) by

$$
\Delta \mathrm{a}_{\mathrm{b}}=1_{\mathrm{o}}-\mathrm{1}_{\mathrm{i}}
$$

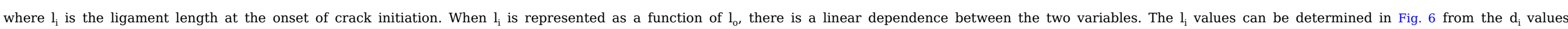

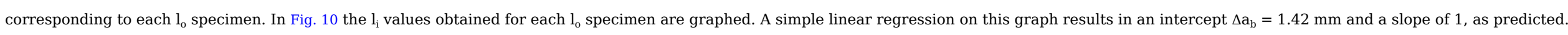

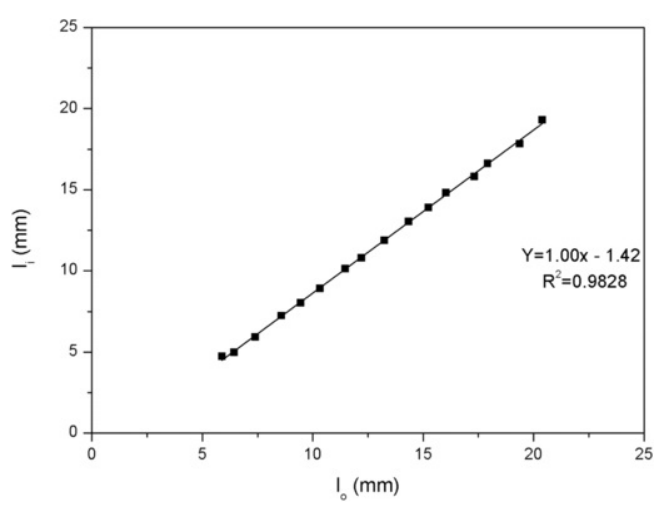

Fig. 10 Determination of $\Delta a_{b}$ for the 16 femtolaser specimens. 
To ensure that the fracture mechanism is the same, irrespective of the ligament length, the specimens must show a common and steady fracture phenomenology during crack growth.

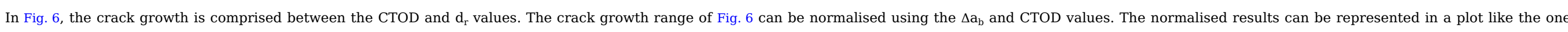

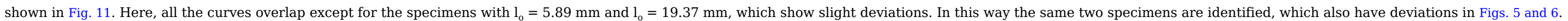

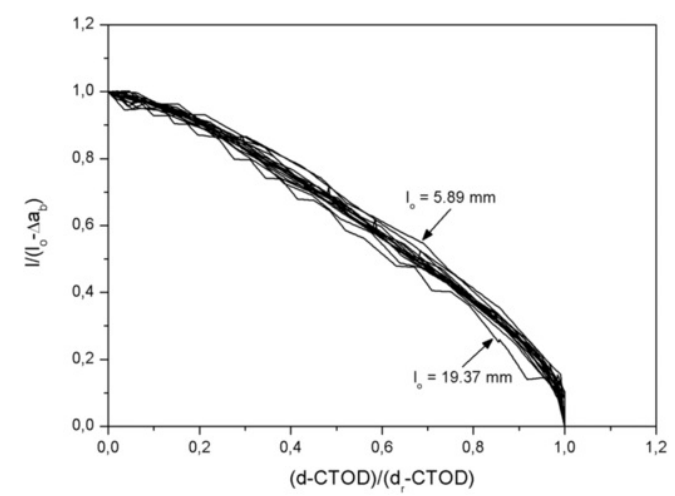

Fig. 11 Normalisation of crack growth for the 16 femtolaser specimens.

alt-text: Fig. 11

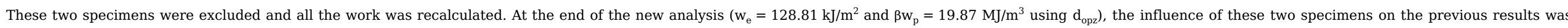
insignificant

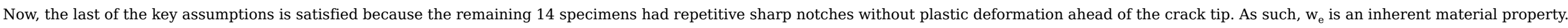

During the crack propagation, the load P versus the crack length a [2] is represented by

$\mathrm{P}=\mathrm{t}(\mathrm{W}-\mathrm{a}) \sigma_{\mathrm{i}}$

and its derivative

$\frac{\mathrm{dP}}{\mathrm{da}}=-\mathrm{t} \sigma_{\mathrm{i}}$

Thus, if $\mathrm{P}$ is represented as a function of a, a straight line with slope $-\mathrm{t}_{\mathrm{i}}$ should be found.

The crack length (Fig. 1) is given by

$\mathrm{a}=\mathrm{W}-1$

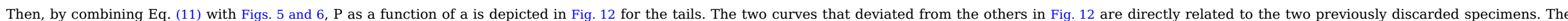

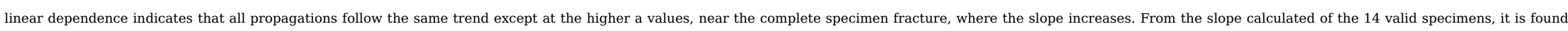
that $\sigma_{i}=25.20 \pm 0.96 \mathrm{MPa}$, which agrees with the previously determined value in Fig. 8. 


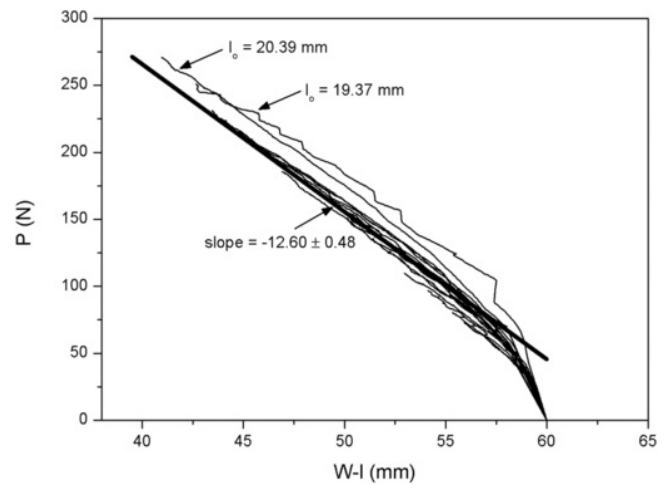

Fig. 12 Load versus a for the 16 femtolaser specimens.

alt-text: Fig. 12

The J-integral concept represents an energy contour path integral that is independent of the path around the crack. The J-integral can be represented [9] as $\mathrm{J}=-\frac{1}{\mathrm{t}}\left(\frac{\mathrm{dU}}{\mathrm{da}}\right)_{\mathrm{d}=\text { constant }}$

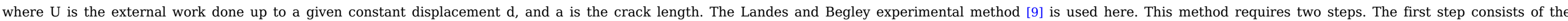

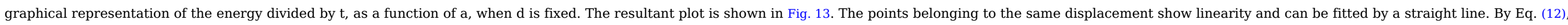
the resultant slope of the regression line is -J. The second step consists of plotting the J values versus displacement, as illustrated in Fig. 14.

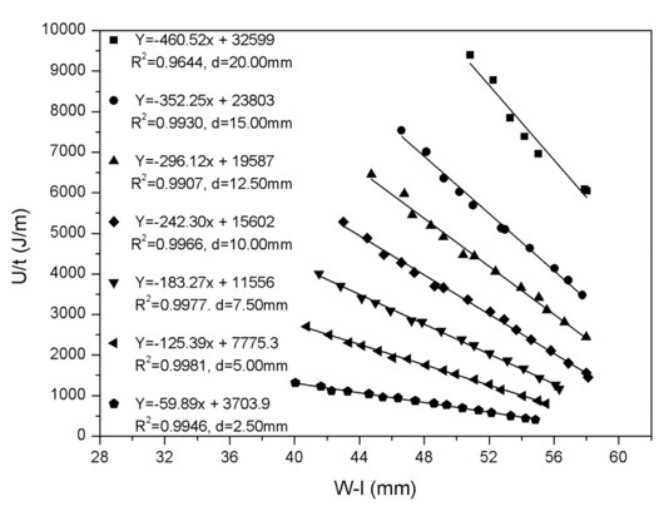

Fig. 13 Input energy divided by thickness versus a for the 14 valid femtolaser specimens. alt-text: Fig. 13 


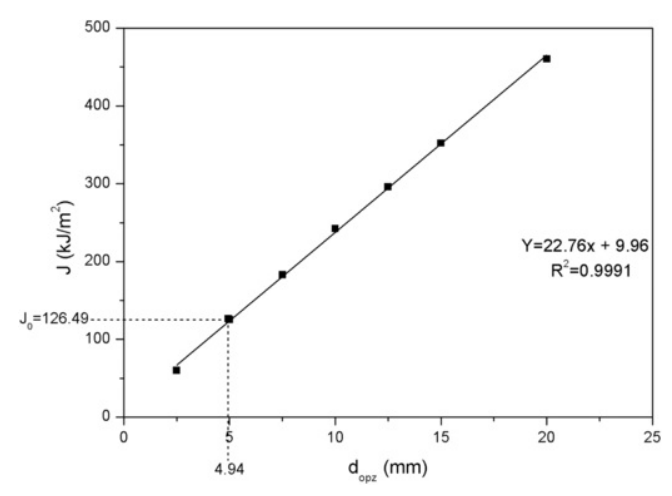

Fig. 14 J-integral plot for the 14 valid femtolaser specimens.

alt-text: Fig. 14

For a non-work hardening material and full yielding of the ligament [2], U/t is a linear function of a at a constant displacement, as it has been verified, then

$\mathrm{J}=\sigma_{\mathrm{i}} \cdot \mathrm{d}$

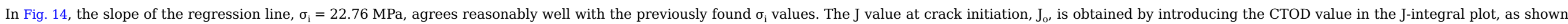
in Fig. 14. This provides a value of $\mathrm{J}_{\mathrm{o}}=126.49 \mathrm{~kJ} / \mathrm{m}^{2}$ that matches well with $\mathrm{w}_{\mathrm{e}}$.

The relationship between $\mathrm{J}_{\mathrm{o}}$ or $\mathrm{w}_{\mathrm{e}}$ and CTOD given [2] by

$$
\mathrm{J}_{\mathrm{o}}=\sigma_{\mathrm{y}} \cdot \mathrm{CTOD}=\mathrm{w}_{\mathrm{e}}
$$

is satisfied.

\subsection{Razor blade specimens}

The load versus $\mathrm{d}_{\mathrm{opz}}$ curves determined during testing are shown in Fig. 15 for each of the 16 specimens tested. Here, there is no overlap of curves observed.

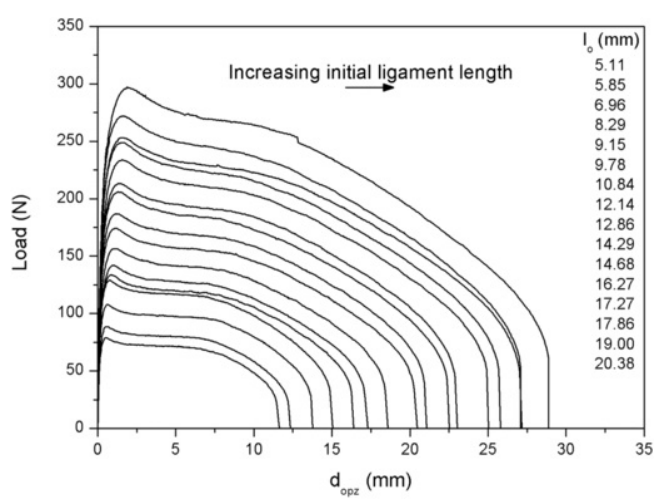

Fig. 15 Registered load versus $d_{\mathrm{opz}}$ curves for the 16 razor blade specimens.

alt-text: Fig. 15

Fig. 16 accounts for the registered data of $\mathrm{l}$ as a function of $\mathrm{d}_{\text {opz }}$. A partial overlap of the specimens with $\mathrm{l}_{\mathrm{o}}=19 \mathrm{~mm}$ and $\mathrm{l}_{\mathrm{o}}=17.86 \mathrm{~mm}$ is observed. 


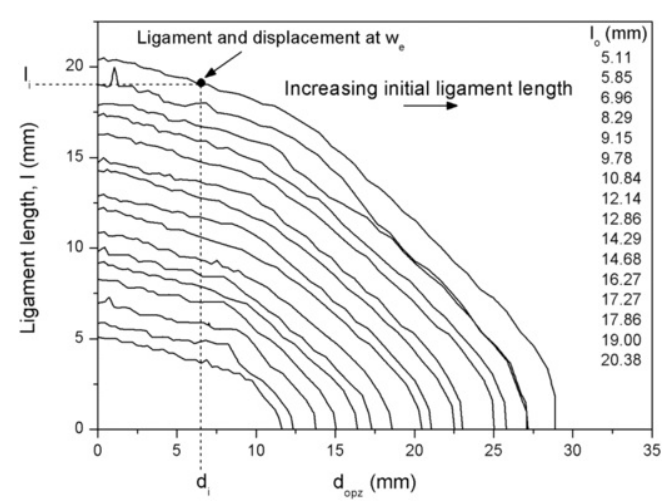

Fig. 16 Registered $l$ versus $d_{\text {opz }}$ curves for the 16 razor blade specimens.

alt-text: Fig. 16

The EWF plot of the 16 specimens, when $\mathrm{d}_{\mathrm{opz}}$ is used, is displayed in Fig. 17. The intercept at $\mathrm{d}_{\text {opz }}=0$ of the regression line yields $\mathrm{w}_{\mathrm{e}}=175.97 \mathrm{~kJ} / \mathrm{m}^{2}$.

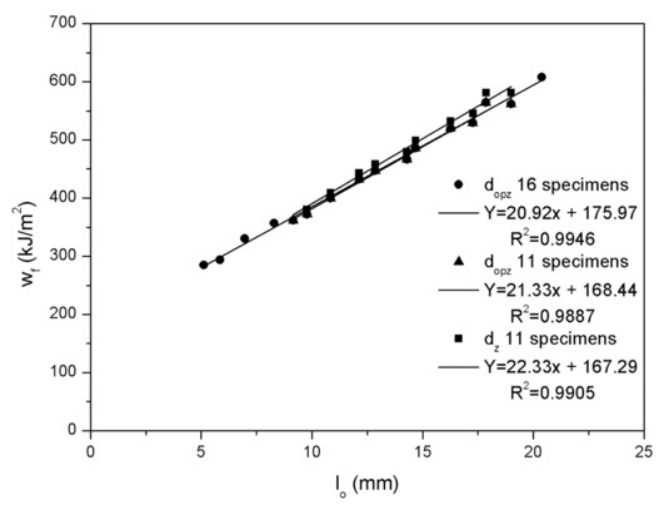

Fig. 17 EWF plot for the razor blade specimens: $\bullet$ ) $d_{\text {opz }} 16$ specimens, $\left.\mathbf{\Lambda}\right) d_{\text {opz }} 11$ specimens, $\left.\square\right) d_{z} 11$ specimens.

alt-text: Fig. 17

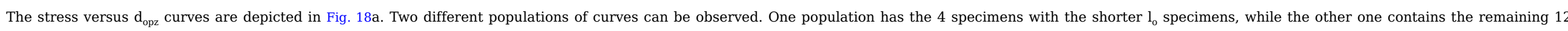
specimens. 



Fig. 18 Stress versus $d_{\mathrm{opz}}$ curves for the razor blade specimens: a) 16 specimens, b) 11 specimens.

alt-text: Fig. 18

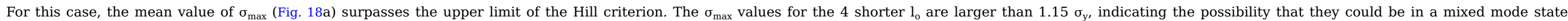
However, this is not the case because the shorter femtolaser specimens, which have similar $\mathrm{l}_{0}$, were in a pure plane stress state. The Clutton criterion (Eq. (6)) is satisfied.

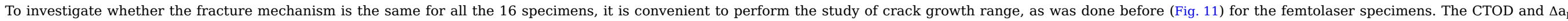

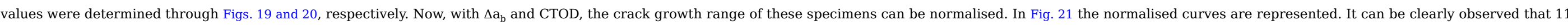
specimens overlap, 4 specimens present large deviations $\left(l_{o}=5.11 \mathrm{~mm}, \mathrm{l}_{\mathrm{o}}=5.85 \mathrm{~mm}, \mathrm{l}_{\mathrm{o}}=6.96 \mathrm{~mm}\right.$ and $\left.\mathrm{l}_{\mathrm{o}}=8.29 \mathrm{~mm}\right)$, and the specimen with $\mathrm{l}_{\mathrm{o}}=20.38 \mathrm{~mm}$ has a slight deviation. 


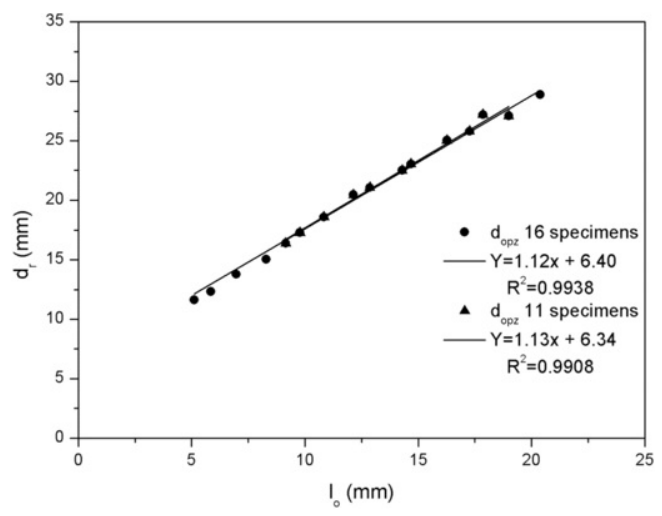

Fig. 19 Determination of CTOD for the razor blade specimens:

$d_{\text {opt }} 16$ specimens, $\left.\mathbf{\Lambda}\right) d_{\text {ops }} 11$ specimens. alt-text: Fig. 19

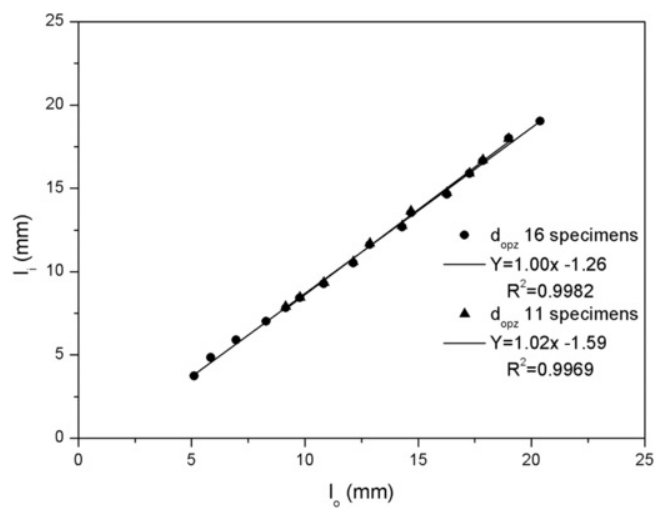

Fig. 20 Determination of $\Delta a_{b}$ for the razor blade specimens: $\bullet$ ) $d_{\text {op }} 16$ specimens, $\left.\Delta\right) d_{\text {op }} 11$ specimens. alt-text: Fig. 20

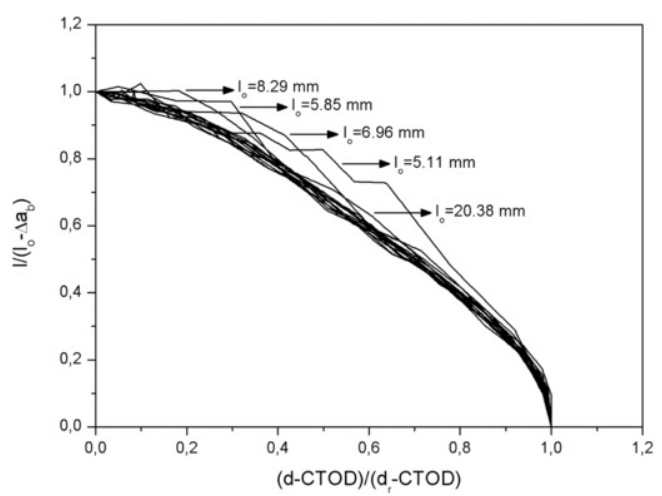

Fig. 21 Normalisation of crack growth for the 16 razor blade specimens.

alt-text: Fig. 21 


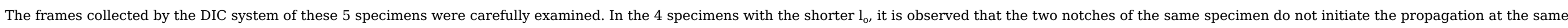

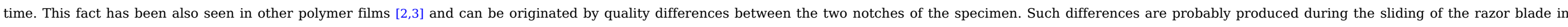
specimens with short $l_{o}$, being more difficult to sharpen that in specimens with large $l_{o}$ value.

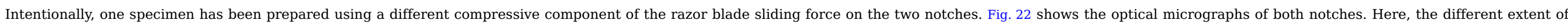
plastic deformation can be observed. A frame of the tested specimen showing the non-simultaneous propagation of both cracks is also shown.

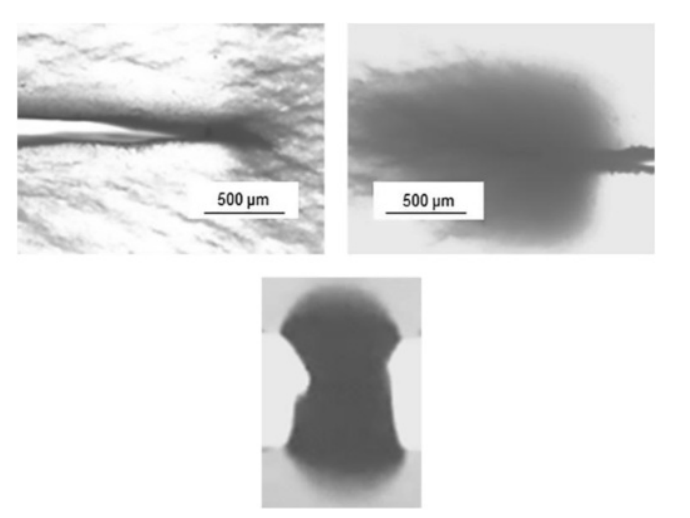

Fig. 22 Non-simultaneous crack propagation.

\section{alt-text: Fig. 22}

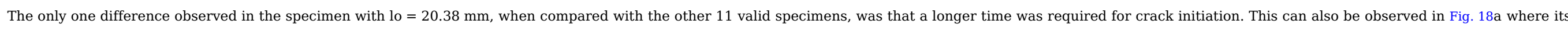

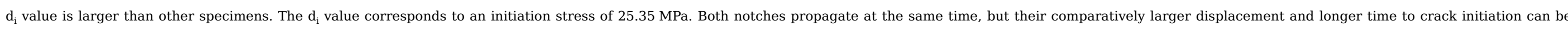
attributed to either their larger crack tip radius, or the increased plastic deformation ahead of the crack tip, despite the parity of the notch quality, when compared to the other 11 valid specimens.

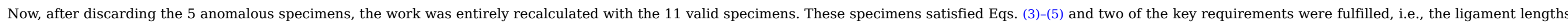

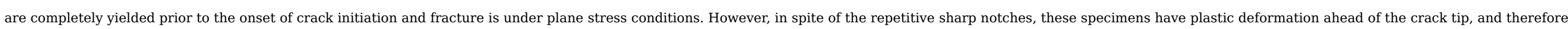
the third key requirement is not accomplished. Thus, $\mathrm{w}_{\mathrm{e}}$ with a value equal to $168.44 \mathrm{~kJ} / \mathrm{m}^{2}$ is not an inherent material property.

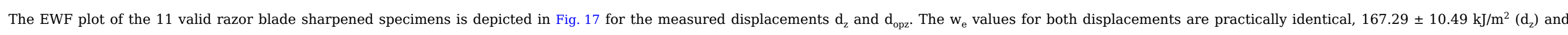

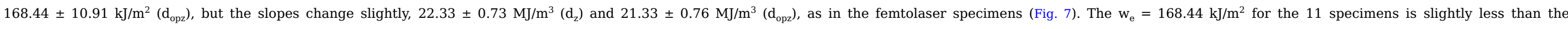
$\mathrm{w}_{\mathrm{e}}=175.97 \mathrm{~kJ} / \mathrm{m}^{2}$ obtained from the 16 specimens.

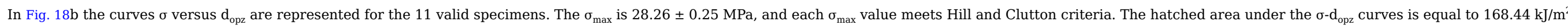

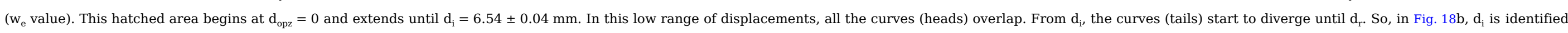

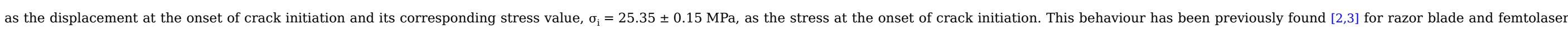
sharpened specimens.

The CTOD value $(6.34 \mathrm{~mm})$ is determined in Fig. 19. As expected, this value is coincident with the $\mathrm{d}_{\mathrm{i}}$ value identified in Fig. $18 \mathrm{~b}$, and $\Delta \mathrm{a}_{\mathrm{b}}=1.59 \mathrm{~mm}$ is obtained in Fig. 20 for the 11 specimens.

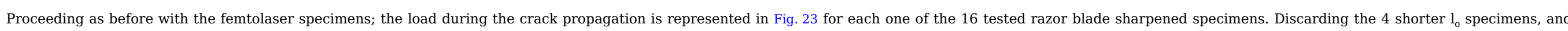

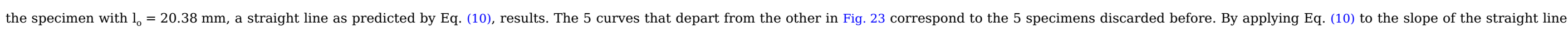
obtained from the 11 valid specimens shown in Fig. 23, it is found that $\sigma_{i}=25.06 \pm 0.88 \mathrm{MPa}$, a value that agrees very well with the $\sigma_{i}$ values determined before. 


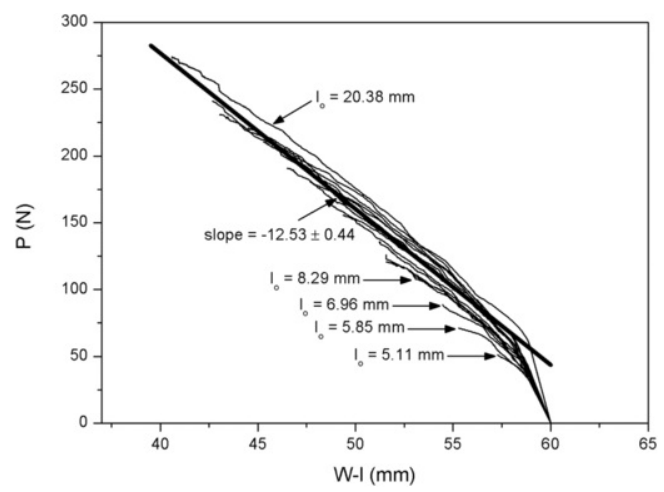

Fig. 23 Load versus a for the 16 razor blade specimens.

\section{alt-text: Fig. 23}

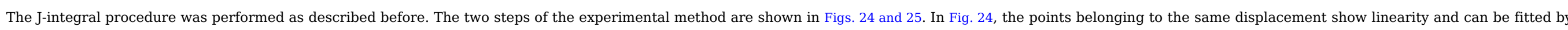

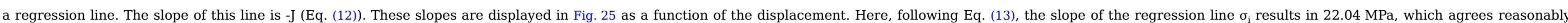
with the $\sigma_{\mathrm{i}}$ value encountered in Fig. 18b. Using the displacement at the onset of crack initiation gives $\mathrm{J}_{\mathrm{o}}=166.01 \mathrm{~kJ} / \mathrm{m}^{2}$, which also agrees with $\mathrm{w}_{\mathrm{e}}$.

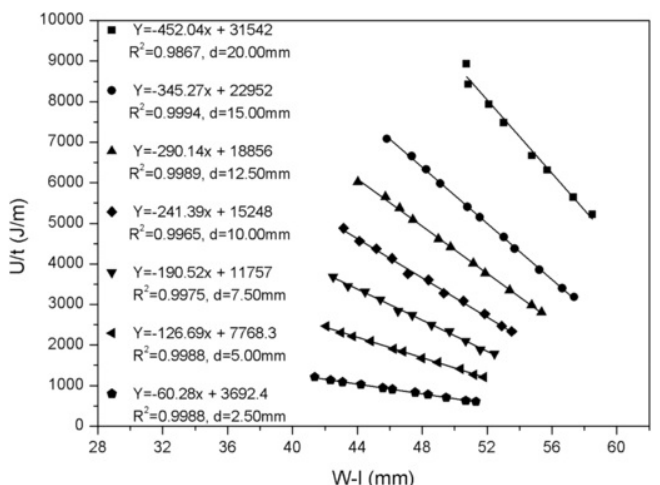

Fig. 24 Input energy divided by thickness versus a for the razor blade specimens.

alt-text: Fig. 24

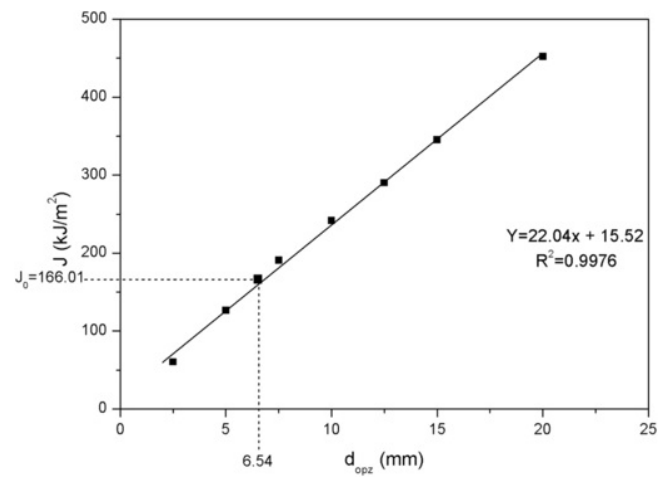




\section{alt-text: Fig. 25}

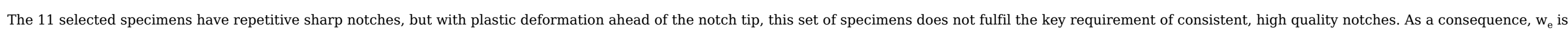

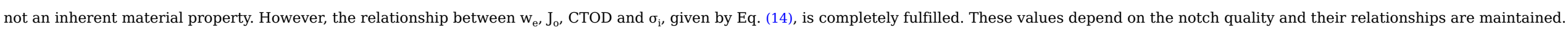

\subsection{Femtolaser versus razor blade}

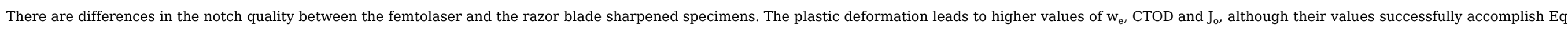
(14).

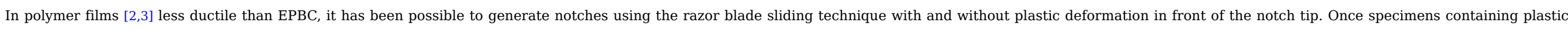
deformation were discarded, the fracture parameters were coincident with those obtained in femtolaser specimens.

The mean $\sigma_{\max }$ and $\sigma_{\mathrm{i}}$ values for the femtolaser and razor blade specimens have the same values. However, the CTOD and $\Delta \mathrm{a}_{\mathrm{b}}$ values are larger for the razor blade sharpened specimens.

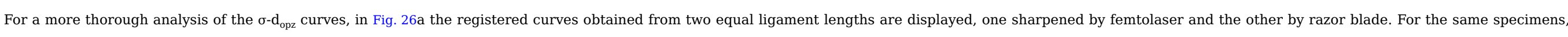

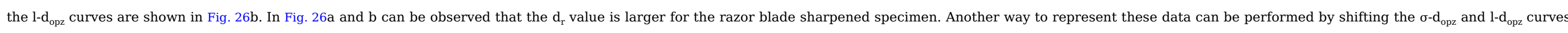

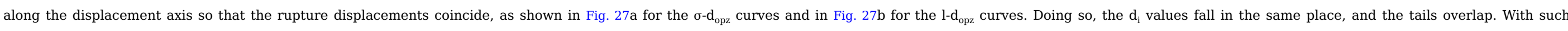

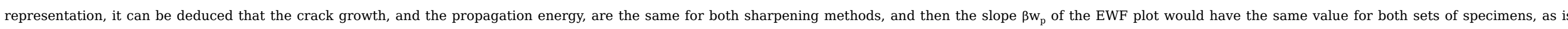

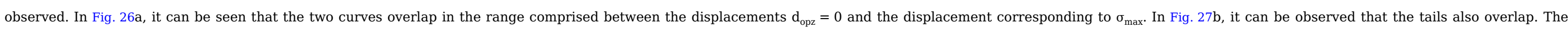
difference between both curves occurs in the range comprised between the displacement corresponding to $\sigma_{\max }$ and $\mathrm{d}_{\mathrm{i}}$. In spite of this, $\sigma_{\mathrm{i}}$ is the same for both notch sharpening procedures. 

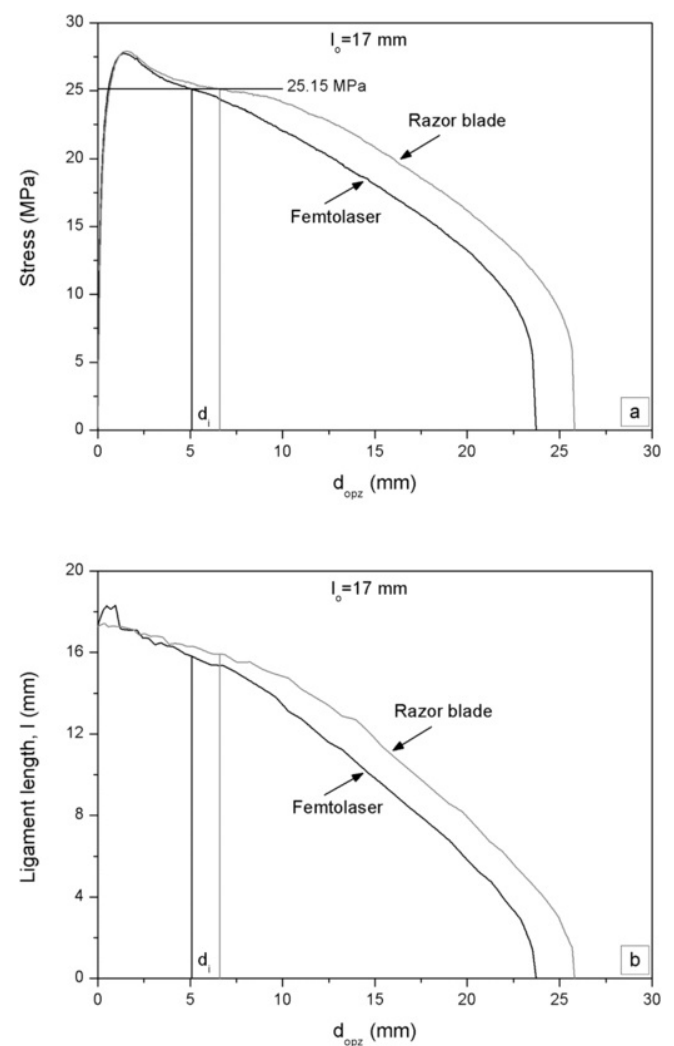

Fig. 26 Femtolaser and razor blade specimens with $\mathrm{l}_{\mathrm{o}}=17 \mathrm{~mm}$ : a) $\sigma$ versus $\mathrm{d}_{\text {opzz }}$, b) $l$ versus $\mathrm{d}_{\mathrm{opz}}$ alt-text: Fig. 26 

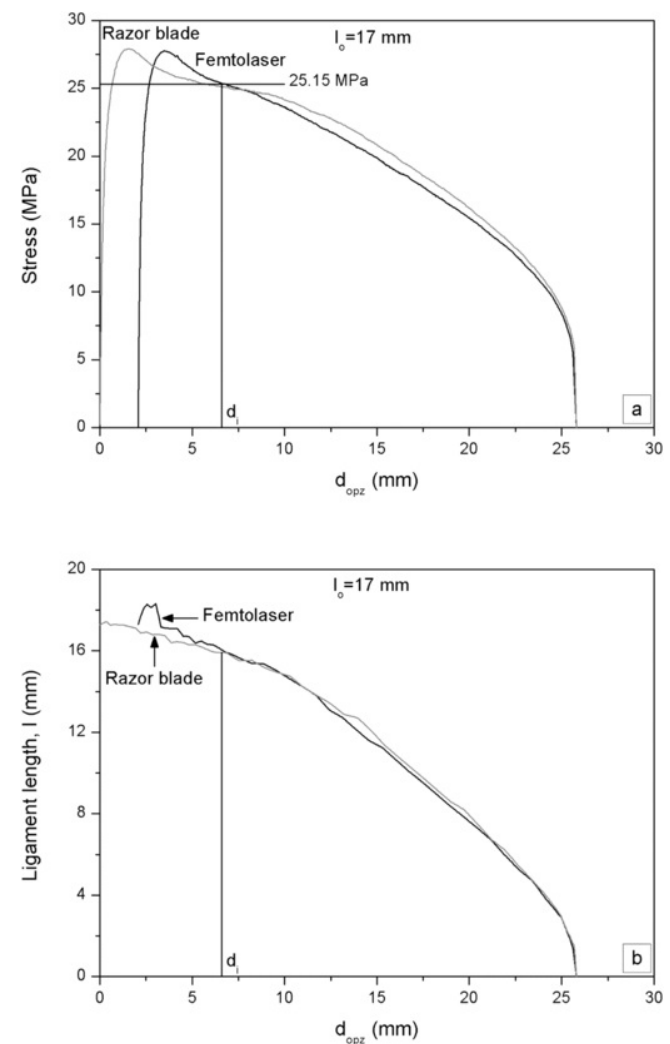

Fig. 27 Femtolaser and razor blade specimens with $\mathrm{l}_{\mathrm{o}}=17 \mathrm{~mm}$ : a) Shifted $\sigma-\mathrm{d}_{\mathrm{opz}}$ b) Shifted $\mathrm{l}-\mathrm{d}_{\mathrm{opz}}$. alt-text: Fig. 27

The same trends have been observed in other ductile polymer films [2,3]. It is clear that the shape of the stress-displacement curves is greatly influenced by the quality of the notches.

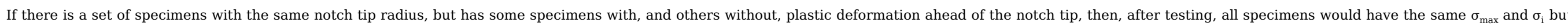

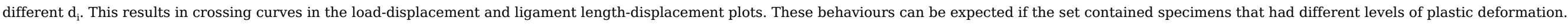

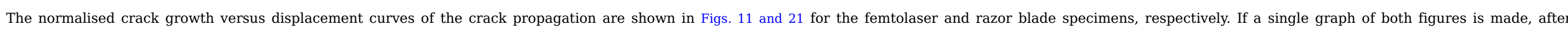

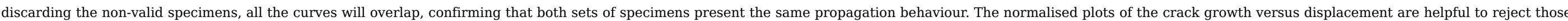
specimens with different quality notches.

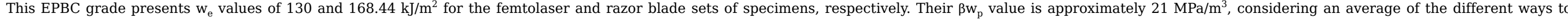

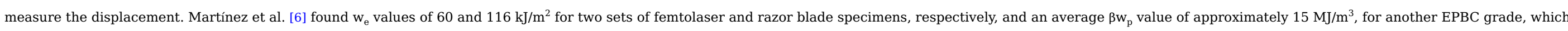
had the same $8.5 \%$ ethylene content but a lower molecular weight. Thus, the increase in molecular weight results in an increase in toughness and in propagation energy.

\subsection{The shape of the stress-displacement curves}

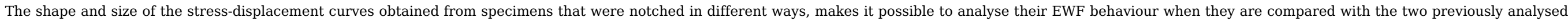
sets of specimens, the femtolaser and the razor blade sharpened specimens. 


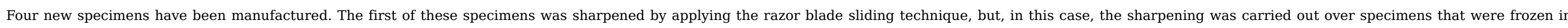

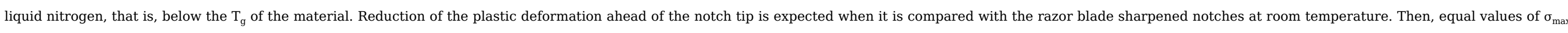

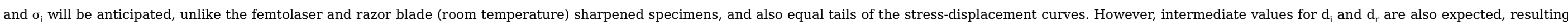
in an intermediate $\mathrm{w}_{\mathrm{e}}$ value.

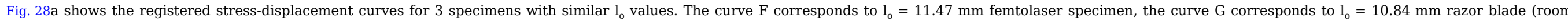

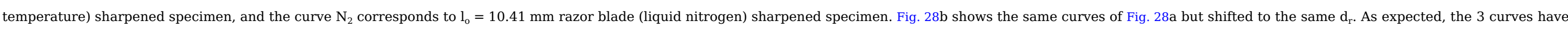
the same $\sigma_{\max }, \sigma_{\mathrm{i}}$, and tails, but the $\mathrm{d}_{\mathrm{i}}$, the CTOD, increases with the plastic deformation, resulting in higher $\mathrm{w}_{\mathrm{e}}$ values.
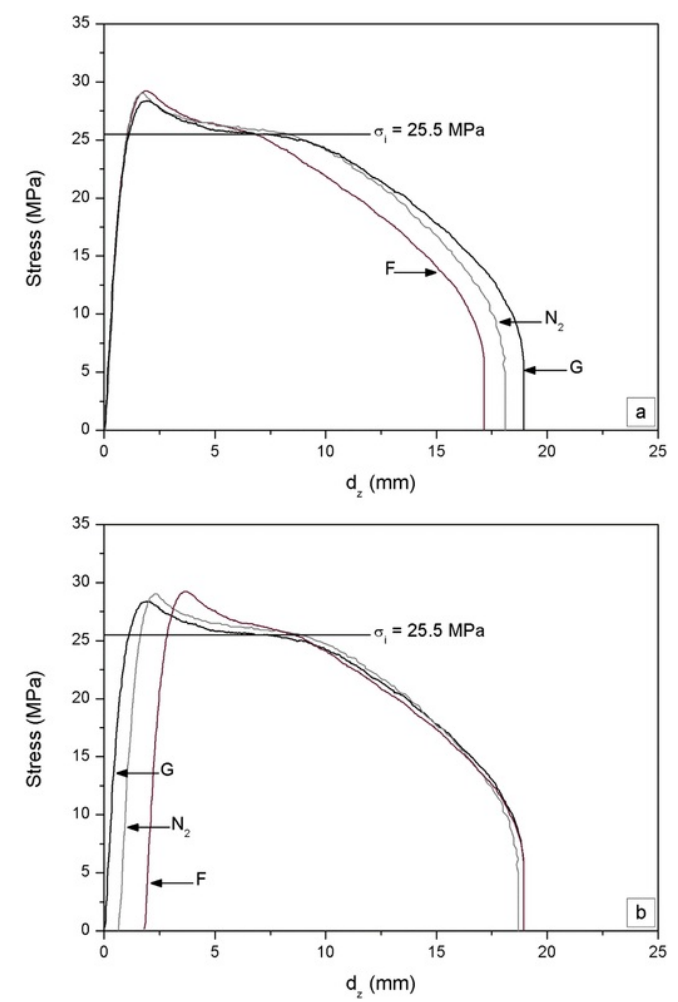

Fig. 28 Stress-displacement curves for F-femtolaser $\left(l_{0}=11.47 \mathrm{~mm}\right)$, G-room temperature razor blade $\left(l_{0}=10.84 \mathrm{~mm}\right)$, and $\mathrm{N}_{2}$-liquid nitrogen razor blade $\left(l_{0}=10.41 \mathrm{~mm}\right)$ : a) Measured displacement, b) Displacement shifted to $\mathrm{d}_{\mathrm{r}}$

\section{alt-text: Fig. 28}

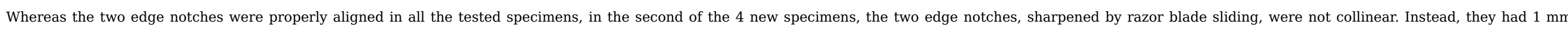

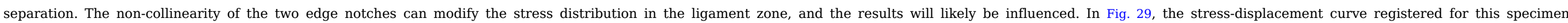

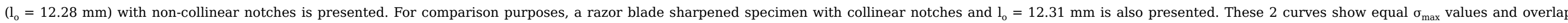

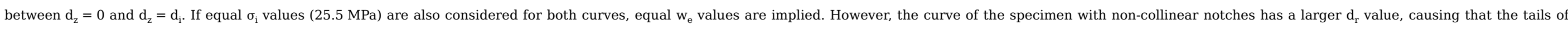
both curves do not overlap. Further, the area of the $\sigma-d_{z}$ curve between $d_{i}$ and $d_{r}$ is also larger, causing $\beta w_{p}$ to be higher for the specimen with non-collinear notches. 


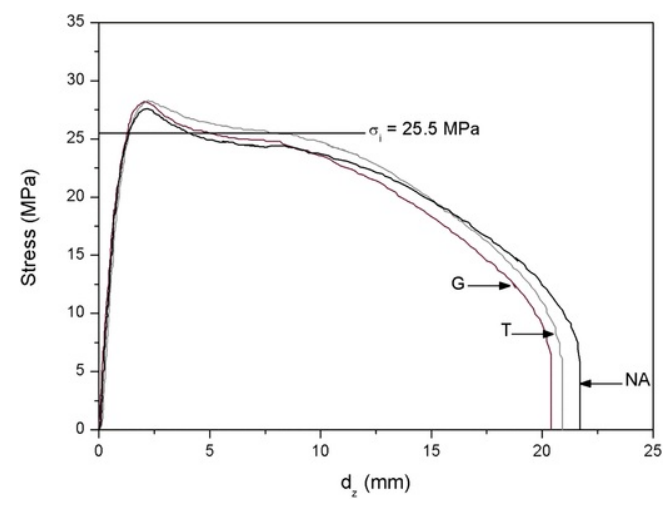

Fig. 29 Stress-displacement curves for G-razor blade collinear notches $\left(l_{0}=12.31 \mathrm{~mm}\right)$, NA-razor blade non-collinear notches $\left(\mathrm{l}_{\mathrm{o}}=12.28 \mathrm{~mm}\right)$, and T-tilted razor blade collinear notches $\left(\mathrm{l}_{0}=12.13 \mathrm{~mm}\right)$

alt-text: Fig. 29

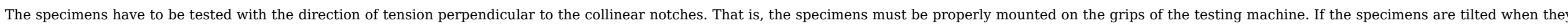

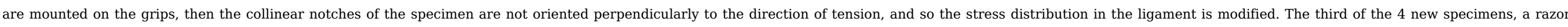

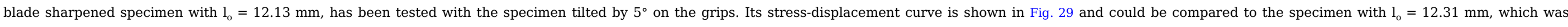

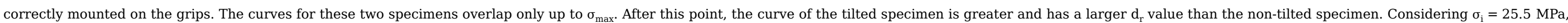
the tilted specimen will have a higher $\mathrm{w}_{\mathrm{e}}$ value than the properly mounted specimen.

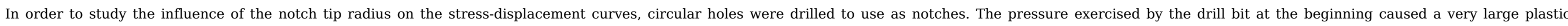

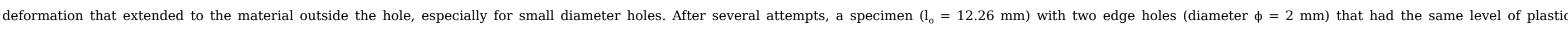

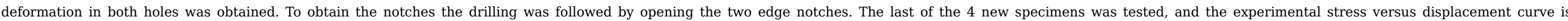

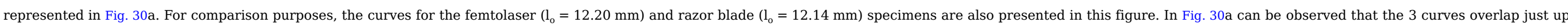

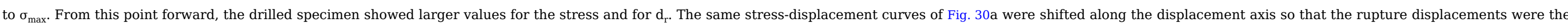

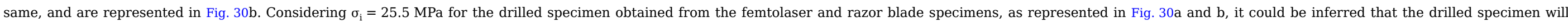
have higher $\mathrm{w}_{\mathrm{e}}, \Delta \mathrm{a}_{\mathrm{b}}$, and CTOD values, while the tail region seems to be quite similar to the other curves. In any case, the influence of the notch tip radius on the fracture parameters is clear 

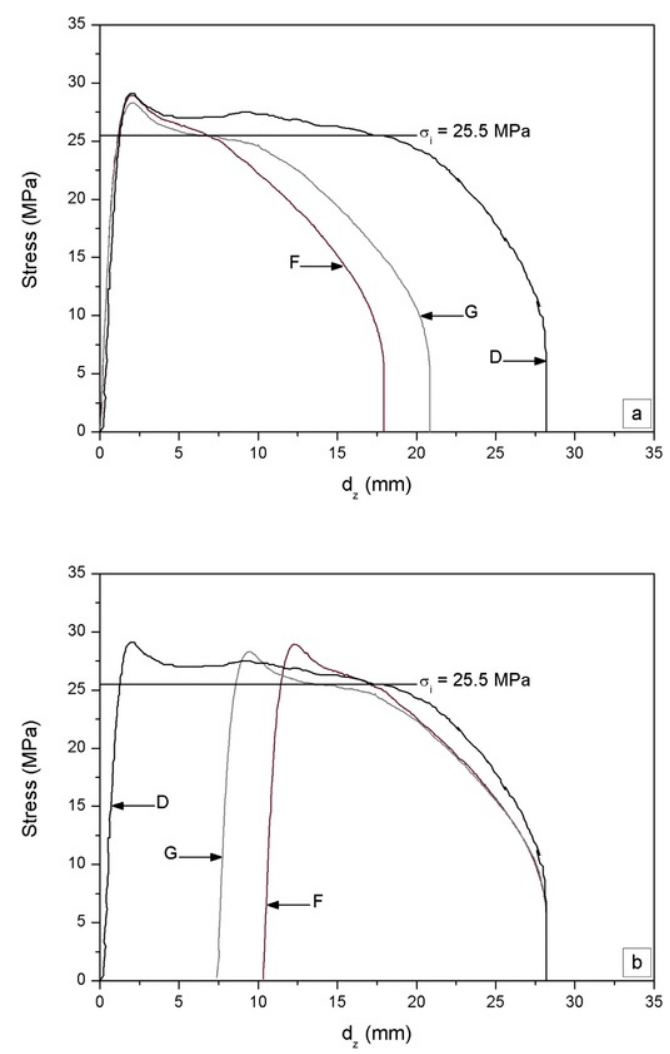

Fig. 30 Stress-displacement curves for F-femtolaser $\left(l_{0}=12.20 \mathrm{~mm}\right)$, G-razor blade $\left(l_{0}=12.14 \mathrm{~mm}\right)$, and D-drilled $\left(l_{0}=12.26 \mathrm{~mm}\right)$ : a) Measured displacement, b) Displacement shifted to $d_{r}$.

\section{alt-text: Fig. 30}

\section{Conclusions}

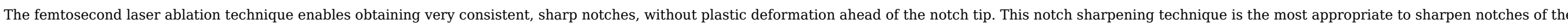
most ductile films and gives the lowest values for the fracture parameters. The limitations include the availability of the equipment and the high cost per notch.

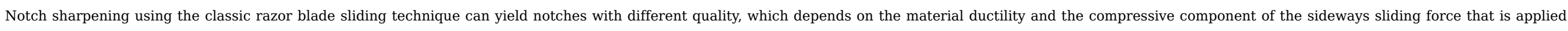

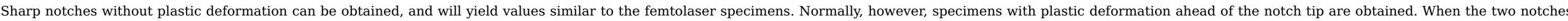

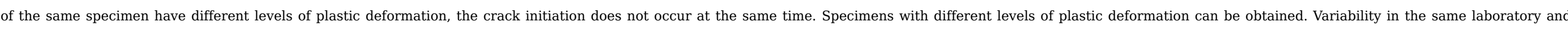

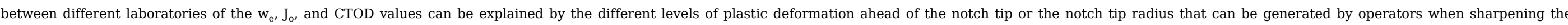

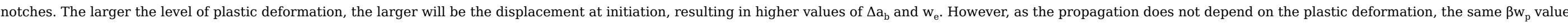
will be obtained.

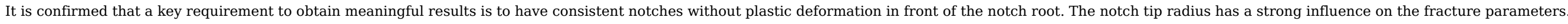

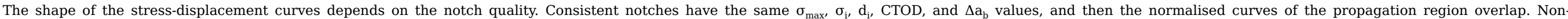
overlapping curves belong to specimens with different quality notches and can be discarded.

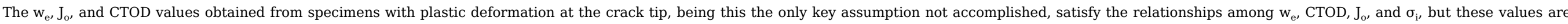


The inspection of the notches in a light optical microscope before testing could be helpful to detect plastic deformation in front of the crack tip.

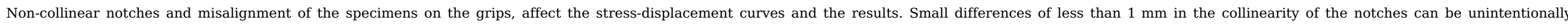

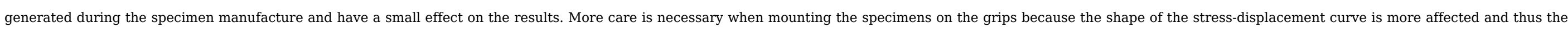
results. Specimens with non-collinear notches and incorrectly aligned can also be detected by normalising the curves in the propagation region.

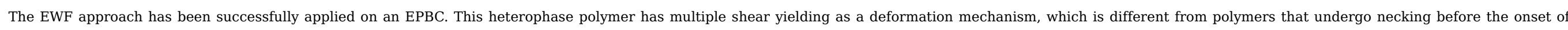
crack propagation. In EPBC, given the same ethylene content, the fracture energy increases as the average molecular weights increase.

\section{Acknowledgements}

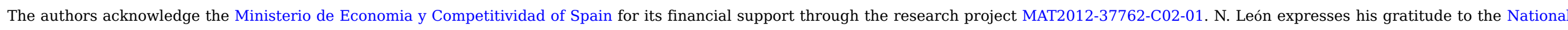
Council for Science and Technology (CONACYT, Mexico) for the predoctoral fellowship.

\section{References}

[1] B. Cotterell and J.K. Reddel, The essential work of plane stress ductile fracture, Int. J. Fract. 13, 1977, 267-277.

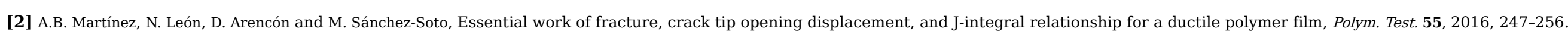

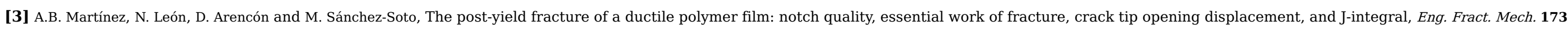
2017, 21-31

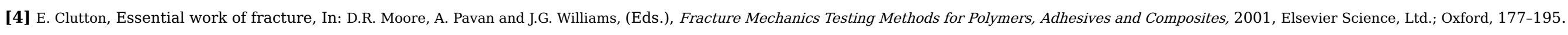

[5] J.G. Williams and M. Rink, The standardisation of the EWF test, Eng. Fract. Mech. 74, 2007, 1009-1017.

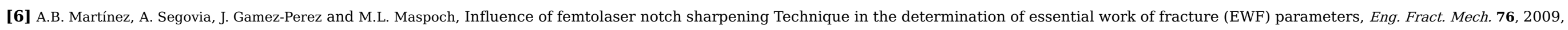
1247-1254.

[7] R. Hill, On discontinuous plastic states, with special reference to localized necking in thin sheets, J. Mech. Phys. Solids 1, 1952, 19-30.

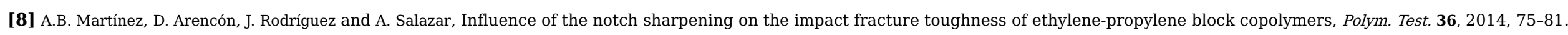

[9] J.A. Begley and J.D. Landes, The J integral as a fracture criterion, In: Fracture Toughness, ASTM STP 514, 1972, American Society for Testing and Materials; Philadelphia, 1-20.

\section{Queries and Answers}

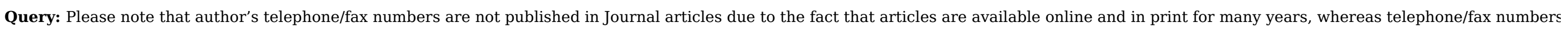
are changeable and therefore not reliable in the long term.

Answer: I agree with your observation.

Query: Please provide the grant number for 'National Council for Science and Technology (CONACYT, Mexico)' if any?

Answer: There is no grant number associated.

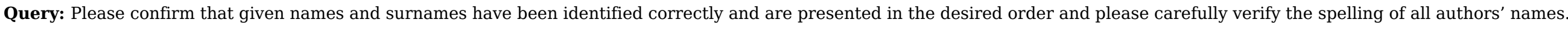

Answer: They are all correct. 